\title{
Correlation between severity of Coronary Artery Disease and severity of Peripheral Artery Disease, a detail analytical study from Eastern India
}

\author{
Saumyajit Ghosh ${ }^{1}$, Sudeb Mukherjee ${ }^{2 *}$, Kaushik Paul ${ }^{3}$ and SC Mandal ${ }^{4}$ \\ Department of Cardiology, ICVS, IPGME\&R, India
}

Submission: August 23, 2018; Published: October 31, 2018

*Corresponding author: Sudeb Mukherjee, Department of Cardiology, ICVS, IPGME\&R, 4/28 A, Jadavgarh, Dr.BC Roy Road, Kolkata-700078, West Bengal, India, Tel:+91-8334014941; Email: drsumukherjee@gmail.com

\begin{abstract}
Introduction: Association betweenPeripheral Artery Disease (PAD) and Coronary Artery Disease (CAD) is well known. Several underlying risk factors which has causative role in the causation of both PAD and CAD are same. Severity of CAD may be associated with severity of PAD considering the pathophysiological similarity behind these diseases.

Methods: 219 patients who were diagnosed case of CAD by Coronary angiography were included in this study. They were categorized according to SYNTAX score(an Angiographic tool to determine the complexity of CAD). They underwent appropriate investigations and Ankle Brachial Pressure Index (ABPI) were calculated. Detail statistical analysis was done accordingly.

Results: Diabetes Mellitus and smoking was found to have statistically siginificant association with the severity of CAD and PAD. Smoking, alcohol, dyslipidemia and systemic hypertension did not achieve statistical significant $p$ value to correlate with the severity of PAD. Increasing age was found to be associated with increase severity of CAD and PAD although statistically not significant. Increase in SYNTAX score was found to be correlated well with increase severity of PAD when ABPI was considered.
\end{abstract}

Conclusion: ABPI might be one of the best screening noninvasive tool to be correlated well with severity of PAD and CAD.

Keywords: Ankle Brachial Pressure Index; Arterial disease; Coronary Artery Disease; SYNTAX Score

Abbreviations: ABPI: Ankle Brachial Pressure Index; PAD: Peripheral Arterial Disease; CAD: Coronary Artery Disease

\section{Introduction}

Coronary heart disease is the most common cause of sudden death. It is also the most common cause of death in people over 65 years old. Men are 10 times more likely to get coronary heart disease than women. Coronary artery disease has a number of well determined risk factors. The most common risk factors include smoking, family history,[1] hypertension, obesity, diabetes, lack of exercise, stress, and high blood lipids[2]. Smoking is associated with about $36 \%$ of cases and obesity $20 \%$ [3]. Lack of exercise has been linked to $7-12 \%$ of cases. High blood cholesterol specifically, serum LDL concentrations is also an independent risk factor. High blood triglycerides may play a role[4].Dietary cholesterol does not appear to have a significant effect on blood cholesterol and thus recommendations about its consumption may not be needed although saturated fat is still a concern[5].

Peripheral Arterial Disease (PAD) is the name given to occlusive disease that occurs in the peripheral or outer arteries of the body, such as the legs. However, if a patient has PAD, it is likely that the same process will be happening in the arteries which supply the brain and heart; leaving the patient at higher risk of suffering a coronary artery disease or stroke.

Peripheral artery disease is often caused by atherosclerosis. In atherosclerosis, fatty deposits (plaques) build up in the artery walls and reduce blood flow. Although the heart is usually the focus of discussion of atherosclerosis, this disease can and usually does affect arteries throughout the body. When it occurs in the arteries supplying blood to the limbs, it causes peripheral artery disease. Less commonly, the cause of peripheral artery disease may be blood vessel inflammation, injury to the limbs, unusual anatomy of the ligaments or muscles, or radiation exposure. The main risk factor is cigarette smoking[6]. Other risk factors include diabetes, high blood pressure, and high blood cholesterol[7]. The underlying mechanism is usually atherosclerosis. PAD is typically diagnosed by finding an Ankle-Brachial Index (ABI) less than 0.90, 
which is the systolic blood pressure at the ankle divided by the systolic blood pressure of the arm. Duplex ultrasonography and angiography may also be used. Angiography is more accurate and allows for treatment at the same time; however, it is associated with greater risks. It is unclear if screening for disease is useful as it has not been properly studied[8]. In those with intermittent claudication from PAD, stopping smoking and supervised exercise therapy improves outcomes[9].Medications, including statins, ACE inhibitors, and cilostazol also may help[10]. Aspirin does not appear to help those with mild disease but is usually recommended in those with more significant disease. Anticoagulants such as warfarin are not typically of benefit[11]. Procedures used to treat the disease include bypass grafting, angioplasty, and atherectomy.

\section{Correlation between CAD \& PAD}

Atherosclerosis, the most common cause of mortality and morbidity worldwide, is considered a generalized process which affects coronary, cerebral, and peripheral arteries of the lower extremities[12].An important issue in clinical practice is coronary artery involvements of the disease due to their related high rate of complications and mortality. Evidence indicated the relation between Peripheral Arterial Disease (PAD) and occurrence of cardiovascular disease and coronary events in patients with or without known Coronary Artery Disease (CAD). Moreover, PAD is associated with an increased incidence of multivessel and obstructive CAD. The mentioned relationship is independent of the presence of other cardiovascular risk factors[13].In most cases, PAD is asymptomatic and therefore underdiagnosed. The clinical presentations of PAD in minority of patients are intermittent claudication, rest pain and ulcer. Both symptomatic and asymptomatic PAD patients are at risk of cardiovascular disease and related mortality. Therefore, identifying patients with PAD especially those with asymptomatic disease in atherosclerotic disease is of high prognostic importance[14].The Ankle-Brachial Index $(\mathrm{ABI})$, calculated by dividing the higher systolic blood pressure of each ankle artery by the higher systolic blood pressure of the upper limbsis a simple and non-invasive tool with high specificity and sensitivity for the diagnosis of PAD [15]. Many studies have also reported its predictive value in CAD in patients suspected of having ischemic heart disease[16].

\section{Aims and Objectives}

Severity of coronary artery disease is determined by coronary angiography, which is a invasive process, costly of and carries some risk. The aims of this study is to investigate a non-invasive method e.g., ABPI, if it can help to detect severity of CAD.

\section{Study type}

Cross sectional observational study.

\section{Studyarea}

Department of Cardiology, IPGME \& R and SSKM Hospital.

\section{Study population}

Admitted patient with Coronary Heart diseases.

\section{Study duration}

February 2016 - August 2017 (18 months).

\section{Inclusion criteria}

a. All previously and recently diagnosed CAD patients who have CAG done.

b. Admitted in department of Cardiology and consented for the study.

\section{Exclusion criteria}

a. Unwilling to participate

b. Previous $\mathrm{H} / \mathrm{o}$ PCI or CABG

c. Known history of peripheral arterial diseases

d. Incomplete investigation

\section{Sample size}

219 Patients were recruited for the study after exclusion.

\section{Sampling procedure}

In each patient, clinical history and risk factors were assessed. Smokers included current and former smokers. Hypertension was diagnosed if systolic arterial pressure exceeded $140 \mathrm{~mm} \mathrm{Hg}$ and/ or diastolic arterial pressure exceeded $90 \mathrm{~mm} \mathrm{Hg}$, or if the patient used antihypertensive drugs. Diabetes mellitus was diagnosed if plasma fasting glucose exceeded $126 \mathrm{mg} / \mathrm{dL}$, postprandial or random blood sugar exceeded $200 \mathrm{mg} / \mathrm{dL}$ or if the patient used hypoglycemic agents. To assess the inflammatory status of the affected limb, before angiography all subjects underwent simultaneous blood sampling from the femoral vein (in the case of CAD_PAD the femoral vein was that of the claudicant limb), aorta, coronary sinus, and an antecubital vein.

\section{Study design}

Data were collected prospectively for 219 consecutive patients. Clinical and demographic characteristics including age; sex; diabetes mellitus, dyslipidemia, hypertension, Detection Evaluation, and Treatment of High Blood Pressure, current and past history of cigarette smoking; and family history of premature CAD were abstracted, In addition, the use of antihypertensive, antidiabetic, or lipid-lowering medications were used as criteria for hyper-tension, diabetes, and dyslipidemia, respectively.Obesity was defined as body mass index (BMI) $>25 \mathrm{~kg} / \mathrm{m} 2$ (WHO criteria). In addition to routine investigations, all patients had their $\mathrm{HbA1C}$ measured on admission, and BMI. Coronary angiography data were obtained from the Phillips software system database that includes detailed angiographic findings of all 219 patients. Obstructive CAD burden was assessed with the help of syntax score. PAD \& CAD patients had an Ankle-Brachial Index (ABI) _0.90 and referred a history of intermittent claudication. Each coronary lesion producing $50 \%$ diameter stenosis in vessels diameter more than $1.5 \mathrm{~mm}$ was scored separately and added together to provide the overall Syntax score, which was calculated prospectively using 
the Syntax score algorithm. The Syntax score was calculated to all 219 patients with CAD. For comparative analysis the study population was divided into 3 groups on the basis of syntax score (group I: - <22, group II: - 22-32, group III: >32).

\section{Statistical procedure}

Statistical analysis was performed using the SPSS 17.0 software package. Continuous variables were expressed as mean \pm Standard Deviation (SD) and categorical variables were expressed as percentage. Differences in three group means or proportions were assessed using independent Pearson chi-square test as appropriate. Analysis was done to compare the differences among the three groups and to determine the factors predicting the presence, severity and complexity of coronary artery score. A 2-tailed $P$ value $<0.05$ was considered statistically significant for all analysis. To ascertain the independent contribution to changes in the syntax score attributable to age, blood sugar and BMI, we constructed a multiple linear regression model with changes in syntax score as the dependent variable. A P value less than 0.05 was considered significant.

The SYNTAX score is a novel anatomical tool characterizing coronary vasculature. Importantly, the SYNTAX score grades the

Table 1: Age and sex distribution according to Syntax Score. complexity of coronary artery disease and does not consider lesion treatment. The SYNTAX score described here predicts outcomes for patients treated with PCI but has less predictable value for patients undergoing treatment with bypass surgery. Complex lesion anatomy poses a greater technical challenge and, consequently, a higher risk of adverse events when treated by percutaneous intervention. In contrast, CABG bypasses the lesion and is thus less influenced by lesion complexity. Furthermore, the SYNTAX score is a useful tool to describe the extent of the coronary artery disease complexity for an individual patient, allows for comparison between patients, and can be used effectively to communicate patient disease complexity between physicians. The goal of the SYNTAX score is to assist the clinician in selecting the optimal revascularization strategy, resulting in the best possible outcome for the individual patient. The SYNTAX score of each patients was calculated from the online calculator of www.SYNTAX score.com.

\section{Results}

The present study consists of 219 patients. The study population was divided into 3 groups on the basis of Syntax score i.e.: Group I-Score <22, Group II-Score 22-32, and Group III- Score $\geq 33$.

\begin{tabular}{|c|c|c|c|c|c|}
\hline & & \multicolumn{4}{|c|}{ Sex wise distribution according to Syntax Score } \\
\hline & & Group I $(<22)$ & Group II (22-32) & Group III $(\geq 33)$ & Total \\
\hline \multicolumn{2}{|c|}{ No. of Patients } & $94(42.92 \%)$ & $104(47.49 \%)$ & $21(9.59 \%)$ & 219 \\
\hline \multirow{2}{*}{ Sex } & Male & $63(67.02 \%)$ & $61(58.65 \%)$ & $15(71.43 \%)$ & $139(63.47 \%)$ \\
\hline & Female & $31(32.98 \%)$ & $43(41.35 \%)$ & $06(28.57 \%)$ & $80(36.53 \%)$ \\
\hline \multirow{2}{*}{ Age (years) } & Mean & 51.51 & 52.48 & 52.95 & 219 \\
\hline & $\pm \mathrm{SD}$ & \pm 7.28 & \pm 7.24 & \pm 7.19 & $P$ value $-<0.005$ \\
\hline
\end{tabular}

Table 1 shows distribution of the study population according to age and sex prevalence. In this study out of 219 patients Diabetes was present in $58(26.48 \%)$ patients. With the increasing syntax score there is increasing number patients with diabetes mellitus, Group I- 20.21\%, Group II- 30.77\% and Group- III 33.33\%. The $\mathrm{p}$ value between three groups for diabetes mellitus found to be significant $(p$ Value $=0.002)$. (Figure 1). Systemic hypertension was present in $46(21.00 \%)$ patients. The $p$ value between three groups for hypertension found to be not significant ( $\mathrm{p}$ Value = 0.124). (Figure 2). Figure 3 showing the impact of dyslipidemia on the syntax score. In our study out of 219 patients dyslipidemia was present in $51(23.29 \%)$ patients. The $\mathrm{p}$ value between three groups for dyslipideia found to be not significant ( $p$ Value $=0.110$ ). Figure 4 showing the impact of Obesity on the syntax score. The $p$ value between three groups for obesity found to be not significant ( $\mathrm{p}$ Value $=0.121$ ). Mean BMI was 25.47, 25,12, 25.15 in three groups respectively. Figure 5 showing the impact of Smoking on the syntax score. The $\mathrm{p}$ value between three groups for smoking found to be significant ( $p$ Value $=0.005$ ). 13.24\% patients were alcoholic. The $\mathrm{p}$ value between three groups for alcohol found to be not significant ( $p$ Value $=0.223$ ). Table 2 shows: sex and mean age and \pm SD value of three different groups according to ABPI. Although the mean age in Group-C is higher than other two groups, but it does not met the statistical significance with p Value 0.468 . With the increasing ABPI there is decreasing number of patients with diabetes mellitus, Group A- 45.83\%, Group B- 26.23\% and Group- C $23.13 \%$. The p value between three groups for diabetes mellitus found to be not significant ( $p$ Value $=0.110$ ) according to ABPI (Figure 6). Figure7 showing the impact of Hypertension on ABPI. Systemic hypertension was present in 46 (21.00\%) patients. The $\mathrm{p}$ value between three groups for hypertension found to be not significant ( $p$ Value $=0.125$ ). Figure 8 showing the impact of Dyslipidemia on ABPI. In this study dyslipidemia was present in $51(23.29 \%)$ patients. The $\mathrm{p}$ value between three groups for dyslipideia found to be not significant ( $p$ Value $=0.092$ ) according to ABPI. Obesity was present in 118 (53.88\%) patients. The $p$ value between three groups of ABPI for obesity found to be not significant $(\mathrm{p}$ Value $=0.170$ ). Figure 9 showing the impact of Smoking on ABPI. In our study out of 219 patients 130 (59.36\%) patients were smokers. The $\mathrm{p}$ value between three groups for 
smoking found to be not significant ( $\mathrm{p}$ Value $=0.077$ ) according to ABPI. The impact of Alcohol on ABPI between three groups found to be not significant ( $p$ Value $=0.088$ ) in this study. There was strong correlation found between SYNTAX score and ABPI with significant statistical value $(r=-0.449$ and $p<0.001$. Table 3 $\& 4$ depicts all variable data in association with SYNTAX and ABPI respectively.

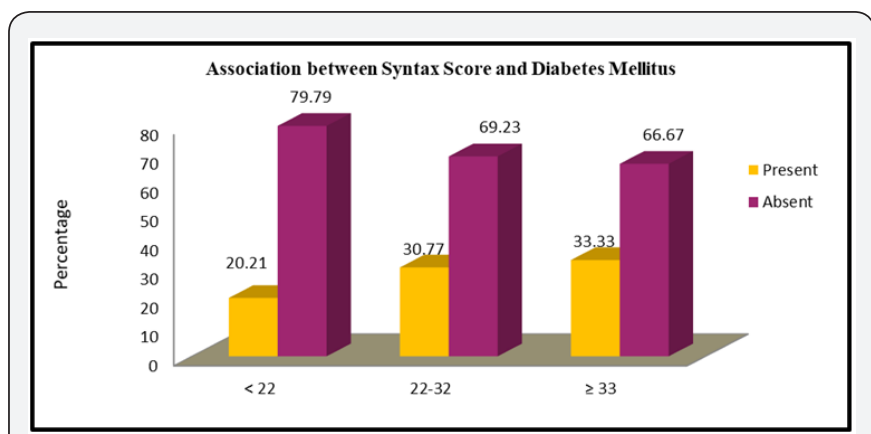

Figure 1: Association between Syntax Score and Diabetes Mellitus.

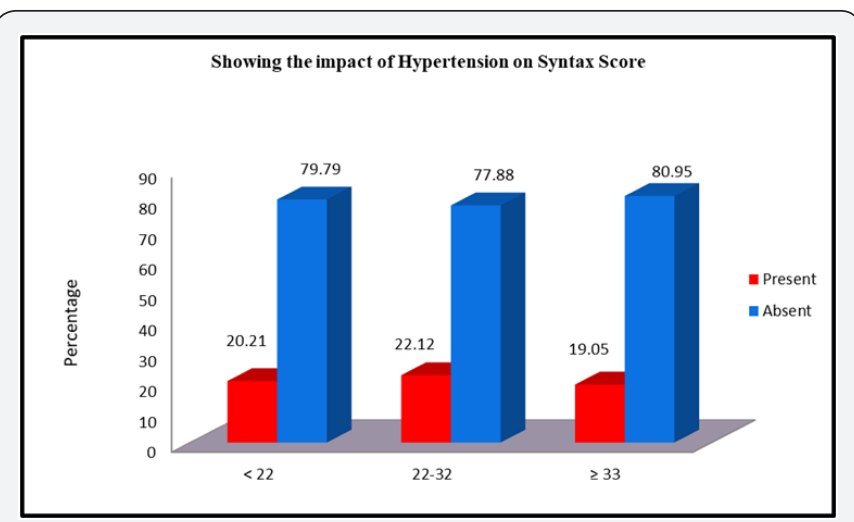

Figure 2: Showing the impact of Hypertension on Syntax Score.

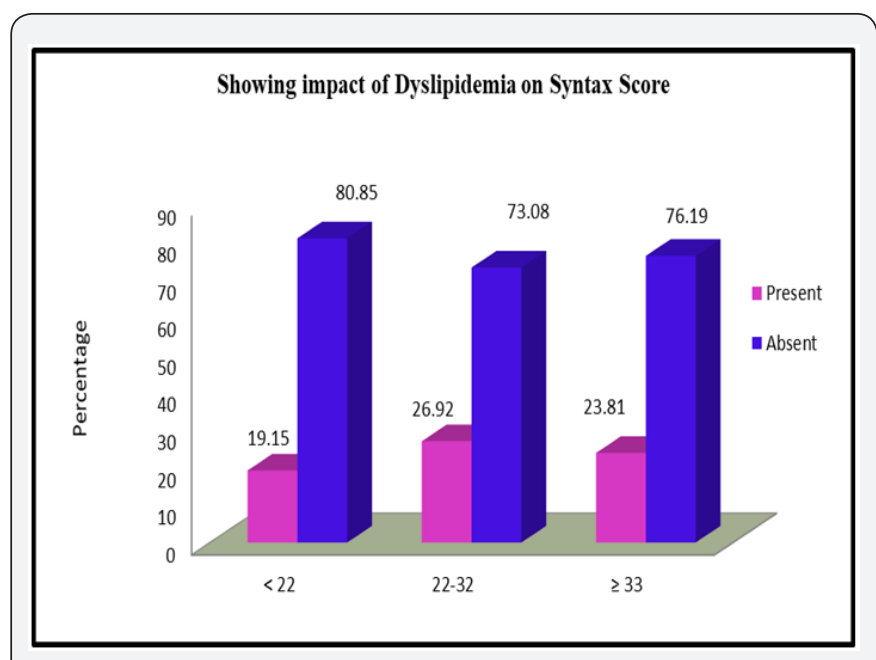

Figure 3: Showing impact of Dyslipidemia on Syntax Score.

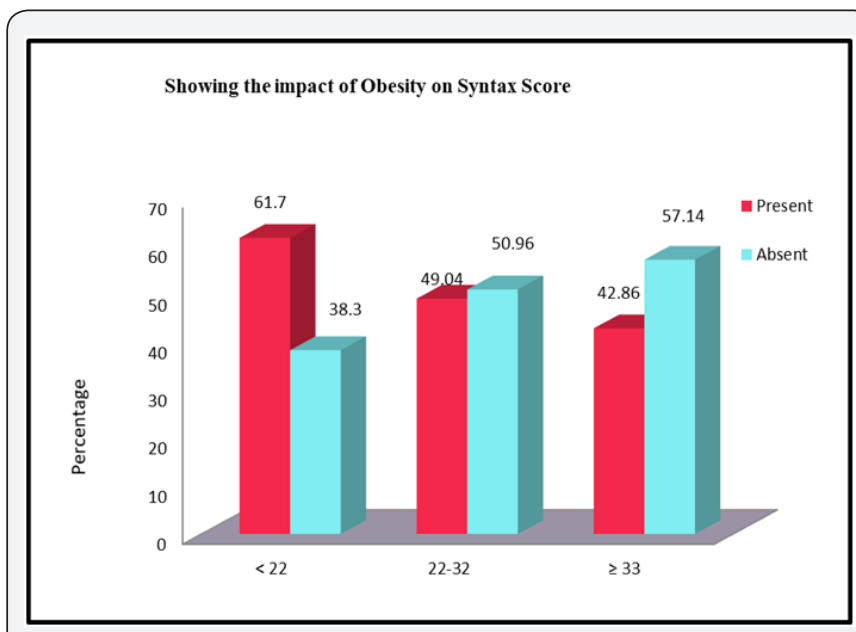

Figure 4: Showing the impact of Obesity on Syntax Score.

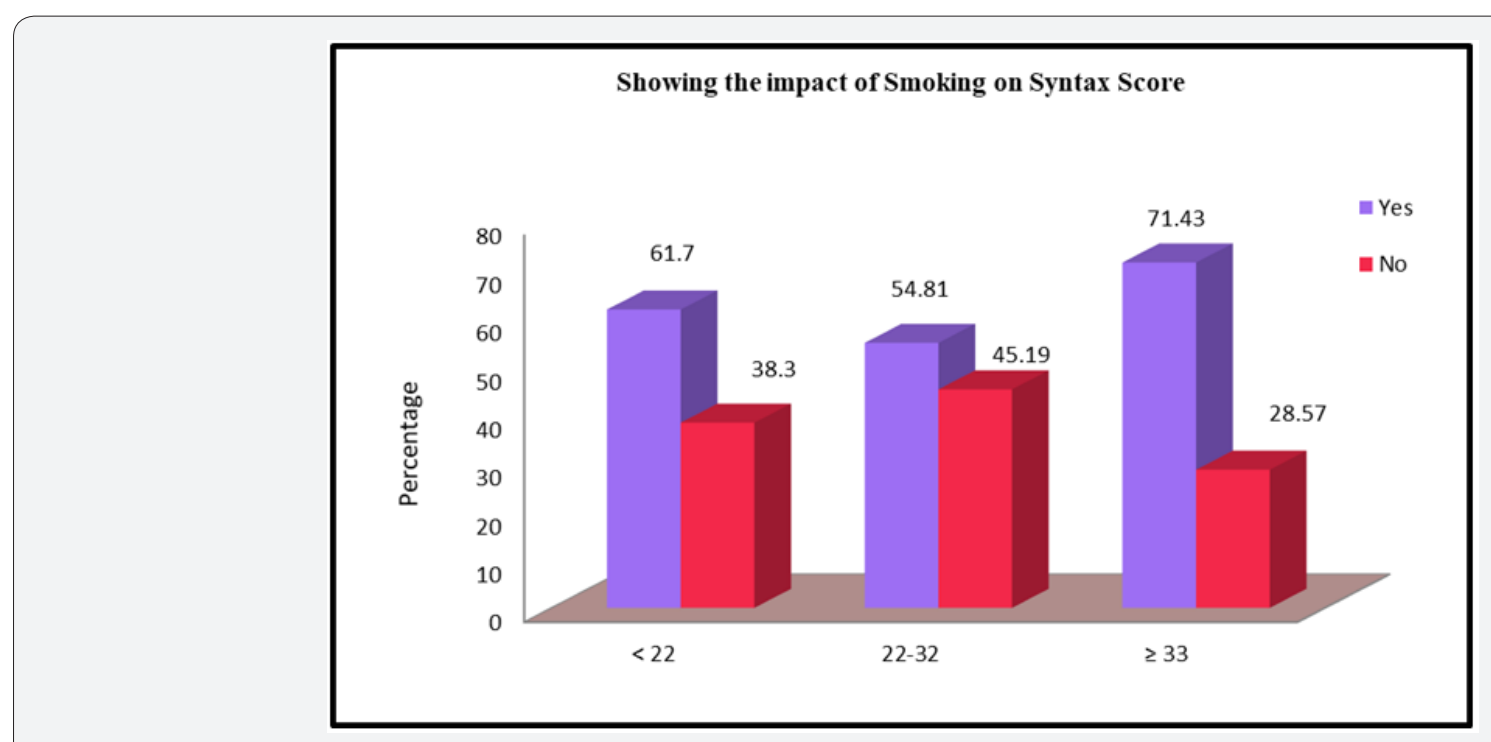

Figure 5: Showing the impact of Smoking on Syntax Score. 
Table 2: Age and sex distribution according to ABPI.

\begin{tabular}{|c|c|c|c|c|c|}
\hline & & \multicolumn{4}{|c|}{ Sex wise distribution according to ABPI } \\
\hline & & Group A $(<0.9)$ & Group B(0.9-1.0) & Group C $(>1.0)$ & Total \\
\hline \multicolumn{2}{|c|}{ No. of Patients } & $24(10.96 \%)$ & $61(27.85 \%)$ & $134(61.19 \%)$ & 219 \\
\hline \multirow{2}{*}{ Sex } & Male & $16(66.67 \%)$ & $36(59.02 \%)$ & $87(64.93 \%)$ & $139(63.47 \%)$ \\
\hline & Female & $8(33.33 \%)$ & $(40.98 \%)$ & $47(35.07 \%)$ & $80(36.53 \%)$ \\
\hline \multicolumn{6}{|c|}{ Mean age of three groups according to ABPI } \\
\hline \multirow{3}{*}{ Age } & Monon & Group A $(<0.9)$ & Group B (0.9-1.0) & Group C ( $>1.0)$ & p Value \\
\hline & Miedin & 51.164 & 50.113 & 51.441 & \multirow{2}{*}{0.468} \\
\hline & \pm SD & 8.018 & 7.476 & 7.008 & \\
\hline
\end{tabular}

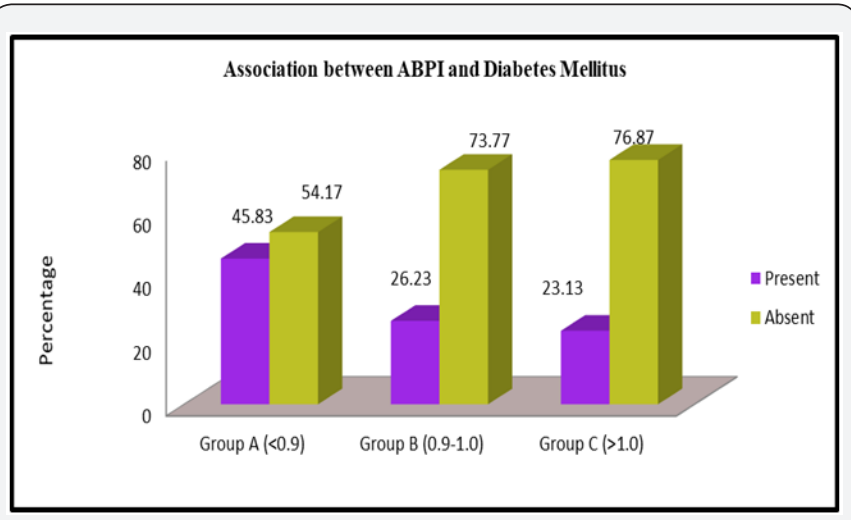

Figure 6: Association between ABPI and Diabetes Mellitus.

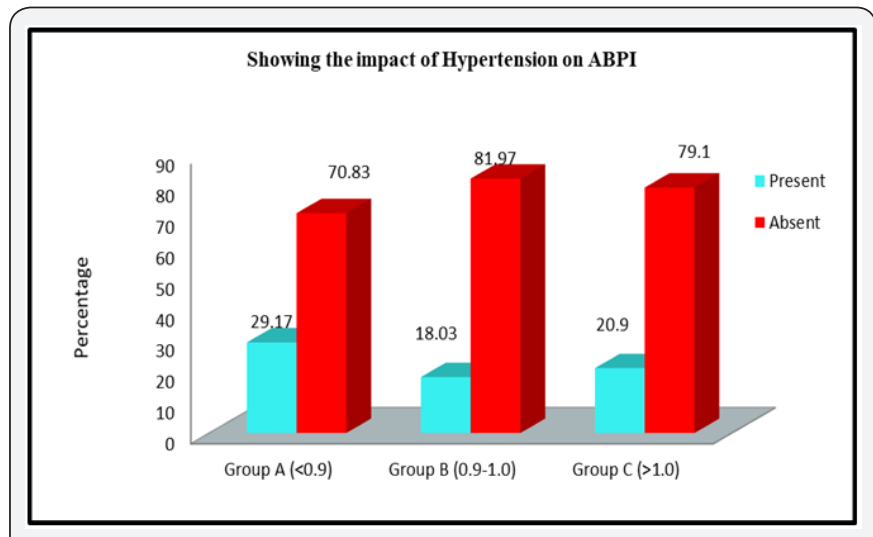

Figure 7: Showing the impact of Hypertension on ABPI.

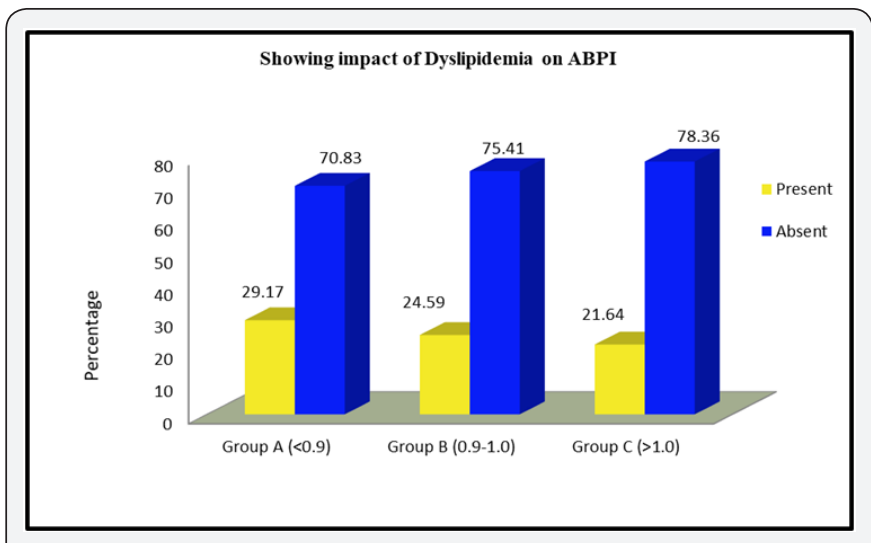

Figure 8: Showing impact of Dyslipidemia on ABPI.

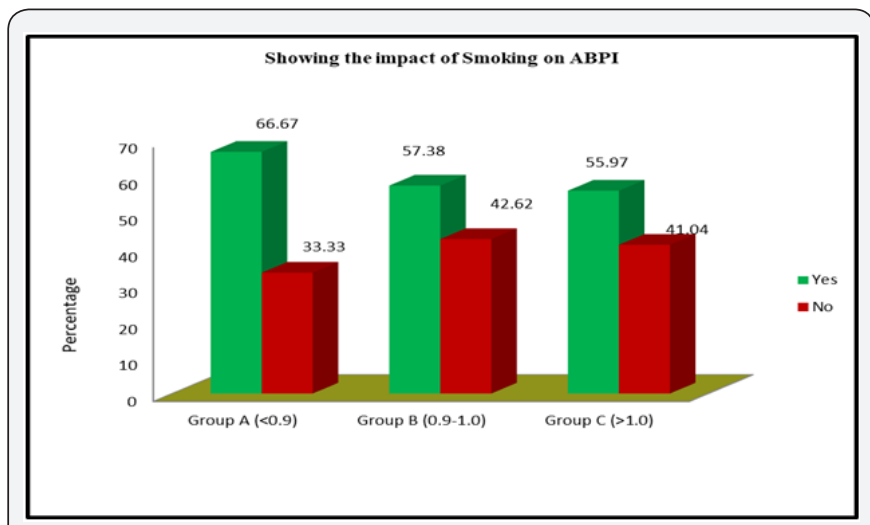

Figure 9: Showing the impact of Smoking on ABPI.

Table 3: Showing Association between Syntax Score and Diabetes mellitus, Hypertension, Obesity, Dyslipidemia, smoking.

\begin{tabular}{|c|c|c|c|c|}
\hline \multirow{2}{*}{ Syntax Score } & \multicolumn{3}{|c|}{ Diabetes Mellitus } & \multicolumn{2}{c|}{ Absent } \\
\cline { 2 - 5 } & \multicolumn{2}{|c|}{ Present Value } \\
\cline { 2 - 5 } & No. of Cases & (\%) & No. of Cases & 79.79 \\
\hline Group I (<22) & 19 & 20.21 & 75 & 69.23 \\
\hline Group II (22-32) & 32 & 30.77 & 72 & 66.67 \\
\hline Group III ( $\geq 33)$ & 07 & 33.33 & 14 & 73.52 \\
\hline Total & 58 & 26.48 & 161 & 0.002 \\
\hline
\end{tabular}




\section{Journal of Cardiology \& Cardiovascular Therapy}

\begin{tabular}{|c|c|c|c|c|c|}
\hline \multirow{3}{*}{ Syntax Score } & \multicolumn{4}{|c|}{ Hypertension } & \multirow{3}{*}{ p Value } \\
\hline & \multicolumn{2}{|c|}{ Present } & \multicolumn{2}{|c|}{ Absent } & \\
\hline & No. of Cases & (\%) & No. of Cases & (\%) & \\
\hline Group I $(<22)$ & 19 & 20.21 & 75 & 79.79 & \multirow{4}{*}{0.124} \\
\hline Group II (22-32) & 23 & 22.12 & 81 & 77.88 & \\
\hline Group III ( $\geq 33$ ) & 04 & 19.05 & 17 & 80.95 & \\
\hline Total & 46 & 21.00 & 173 & 79.00 & \\
\hline \multirow{3}{*}{ Syntax Score } & \multicolumn{4}{|c|}{ Dyslipidemia } & \multirow{3}{*}{ p Value } \\
\hline & \multicolumn{2}{|c|}{ Present } & \multicolumn{2}{|c|}{ Absent } & \\
\hline & No. of Cases & (\%) & No. of Cases & (\%) & \\
\hline Group I $(<22)$ & 18 & 19.15 & 76 & 80.85 & \multirow{4}{*}{0.110} \\
\hline Group II (22-32) & 28 & 26.92 & 76 & 73.08 & \\
\hline Group III ( $\geq 33$ ) & 5 & 23.81 & 16 & 76.19 & \\
\hline Total & 51 & 23.29 & 168 & 76.71 & \\
\hline \multirow{3}{*}{ Syntax Score } & \multicolumn{4}{|c|}{ Obesity } & \multirow{3}{*}{ p Value } \\
\hline & \multicolumn{2}{|c|}{ Present } & \multicolumn{2}{|c|}{ Absent } & \\
\hline & No. of Cases & $(\%)$ & No. of Cases & (\%) & \\
\hline Group I $(<22)$ & 58 & 61.70 & 36 & 38.30 & \multirow{4}{*}{0.121} \\
\hline Group II (22-32) & 51 & 49.04 & 53 & 50.96 & \\
\hline Group III ( $\geq 33$ ) & 9 & 42.86 & 12 & 57.14 & \\
\hline Total & 118 & 53.88 & 101 & 46.12 & \\
\hline \multirow{3}{*}{ Syntax Score } & \multicolumn{4}{|c|}{ Smoking } & \multirow{3}{*}{ p Value } \\
\hline & \multicolumn{2}{|c|}{ Yes } & \multicolumn{2}{|c|}{ No } & \\
\hline & No. of Cases & $(\%)$ & No. of Cases & (\%) & \\
\hline Group I $(<22)$ & 58 & 61.70 & 36 & 38.30 & \multirow{4}{*}{0.005} \\
\hline Group II (22-32) & 57 & 54.81 & 47 & 45.19 & \\
\hline Group III ( $\geq 33$ ) & 15 & 71.43 & 06 & 28.57 & \\
\hline Total & 130 & 59.36 & 89 & 40.64 & \\
\hline
\end{tabular}

Table 4: Showing Association between ABPI and Diabetes Mellitus, hypertension, Dyslipidemia, Obesity and smoking.

\begin{tabular}{|c|c|c|c|c|c|}
\hline \multirow{3}{*}{ ABPI } & \multicolumn{4}{|c|}{ Diabetes Mellitus } & \multirow{3}{*}{ p Value } \\
\hline & \multicolumn{2}{|c|}{ Present } & \multicolumn{2}{|c|}{ Absent } & \\
\hline & No. of Cases & (\%) & No. of Cases & $(\%)$ & \\
\hline Group A $(<0.9)$ & 11 & 45.83 & 13 & 54.17 & \multirow{4}{*}{0.110} \\
\hline Group B (0.9-1.0) & 16 & 26.23 & 45 & 73.77 & \\
\hline Group C (>1.0) & 31 & 23.13 & 103 & 76.87 & \\
\hline Total & 59 & 26.94 & 160 & 73.06 & \\
\hline \multirow{3}{*}{ ABPI } & \multicolumn{4}{|c|}{ Hypertension } & \multirow{3}{*}{ p Value } \\
\hline & \multicolumn{2}{|c|}{ Present } & \multicolumn{2}{|c|}{ Absent } & \\
\hline & No. of Cases & (\%) & No. of Cases & $(\%)$ & \\
\hline Group A $(<0.9)$ & 07 & 29.17 & 17 & 70.83 & \multirow{4}{*}{0.125} \\
\hline Group B (0.9-1.0) & 11 & 18.03 & 50 & 81.97 & \\
\hline Group C (>1.0) & 28 & 20.90 & 106 & 79.10 & \\
\hline Total & 46 & 25.57 & 163 & 74.43 & \\
\hline \multirow{3}{*}{ ABPI } & \multicolumn{4}{|c|}{ Dyslipidemia } & \multirow{3}{*}{ p Value } \\
\hline & \multicolumn{2}{|c|}{ Present } & \multicolumn{2}{|c|}{ Absent } & \\
\hline & No. of Cases & (\%) & No. of Cases & (\%) & \\
\hline
\end{tabular}


Journal of Cardiology \& Cardiovascular Therapy

\begin{tabular}{|c|c|c|c|c|c|}
\hline Group A $(<0.9)$ & 07 & 29.17 & 17 & 70.83 & \multirow{4}{*}{0.092} \\
\hline Group B (0.9-1.0) & 15 & 24.59 & 46 & 75.41 & \\
\hline Group C (>1.0) & 29 & 21.64 & 105 & 78.36 & \\
\hline Total & 51 & 23.29 & 168 & 76.71 & \\
\hline \multirow{3}{*}{ ABPI } & \multicolumn{4}{|c|}{ Obesity } & \multirow{3}{*}{ p Value } \\
\hline & \multicolumn{2}{|c|}{ Present } & \multicolumn{2}{|c|}{ Absent } & \\
\hline & No. of Cases & (\%) & No. of Cases & (\%) & \\
\hline Group A $(<0.9)$ & 11 & 45.83 & 13 & 54.17 & \multirow{4}{*}{0.170} \\
\hline Group B (0.9-1.0) & 32 & 52.46 & 29 & 47.54 & \\
\hline Group C (>1.0) & 75 & 55.97 & 59 & 44.03 & \\
\hline Total & 118 & 53.88 & 101 & 46.12 & \\
\hline \multirow{3}{*}{ ABPI } & \multicolumn{4}{|c|}{ Smoking } & \multirow{3}{*}{ p Value } \\
\hline & \multicolumn{2}{|c|}{ Yes } & \multicolumn{2}{|c|}{ No } & \\
\hline & No. of Cases & (\%) & No. of Cases & $(\%)$ & \\
\hline Group A $(<0.9)$ & 16 & 66.67 & 8 & 33.33 & \multirow{4}{*}{0.077} \\
\hline Group B (0.9-1.0) & 35 & 57.38 & 26 & 42.62 & \\
\hline Group C (>1.0) & 79 & 55.97 & 55 & 41.04 & \\
\hline Total & 130 & 59.36 & 89 & 40.64 & \\
\hline
\end{tabular}

\section{Discussion}

Our study was carried out to find out whether the severity of CAD is correlated with severity of PAD as well as risk factors in patients with coronary artery disease- like Diabetes mellitus, Hypertension, smoking, advancing age, Dyslipidemia, obesity, family history of coronary artery disease, correlate with the severity of coronary atherosclerosis detected by coronary angiography, as they are well recognized for their association with clinical events and acute coronary syndromes. A number of scores have been described in the past for grading the severity of coronary artery disease on angiography like Genisini score[17], Jenkins score[18], syntax score and Friesingers score[19]. We used the syntax scoring system for assessing the coronary atherosclerotic disease burden. We chose this because of its simplicity and syntax score is widely accepted as a CAD burden marker and its prognostic value has been demonstrated in different clinical situations.

Three groups has been categorized according to Ankle brachial pressure index in this study. Group-A, B, C as patient having low $\mathrm{ABPI}<0.9$, between 0.9 to 1 and $>1$ respectively. Mean age in Group-C is higher than other two groups, which met the statistical significance with $p$ Value $<0.005$. There is also gradual increase in mean age of patient's syntax score in Group I to Group III, which met the statistical significance with $p$ Value $<0.005$. This study shows with increasing age syntax score gets increased and associated ABPI suggestive of PAD. The increase of severity of PAD with ageing could be explained by increasing incidence of atherosclerosis in older people, in addition to other risk factors of CAD. Age related changes are due to increase in fibrinogen, coagulation factor (V,VIII,IX,XII a), Von Willebrand factor, altered platelet phospholipid contents and increased platelet activity . All the changes also potentiate development of atherosclerosis[20].
This result also supports the study of Bhattacharya et al[21],where they also found that advancing age is also a factor determining the increase of severity of CAD and PAD.

The impact of Diabetes Mellitus on the syntax score was found to be significant in this study. With the increasing syntax score there is increasing number patients with diabetes mellitus, (Group I- 20.21\%, Group II- 30.77\% and Group- III 33.33\%.).The $\mathrm{p}$ value between three groups for diabetes mellitus found to be significant $(p$ Value $=0.002$ ). Studies of angiographic progression of CAD using serial quantitative angiography to define predictors of severity or progression of disease burden including CASS registry[22] have also consistently identified diabetes as an independent predictor of severity or disease progression. Atherosclerosis affects the coronary arteries of diabetic patients more severely and diffusely than those of non-diabetics. Berry et al[23] found that fasting blood glucose, $\mathrm{HbA} 1 \mathrm{c}$, and presence of diabetes were associated with the severity and progression of coronary atherosclerosis. The impact of systemic hypertension, Dyslipidemia and obesity on the syntax score in this study was not found to be significant. The impact of Smoking on the syntax score between three groups found to be significant ( $p$ Value $=0.005$ ). Alcohol was not found to be a significant causative association in this study. The correlation between Syntax Score and ABPI and the $\mathrm{p}$ Value found to be significant ( $\mathrm{p}$ Value = $<0.001$ ). Several previous reports showed a clear inverse relation between ABI and SS. This study results are similar to previous studies done by Korkmaz et al[24].Benyakorn et al [25]also demonstrated a significant negative correlation between ABI and SS, but theirs was a different population, which included a large proportion of patients with valvular disease and included all age groups[25].Prevalence of PAD in patients undergoing 
PCI with CAD varies from $5 \%$ to $40 \%$ in several studies[26]. The broad range of the PAD prevalence is most likely due to the patients' diverse population backgrounds, demographics, and manifestations of CAD. Our study demonstrates the discrete prevalence of PAD is $10.96 \%$ in patients undergoing CABG or PCI for CAD and the association between PAD and CAD severity. Considering that the patients with CAD and PAD who undergo PCI experience reduced procedural success and increased short- and long-term mortality[27],this high prevalence of PAD in patients undergoing PCI arouse the physicians to the importance of early detection and proper management of peripheral vascular diseases. ABPI measurement is widely accepted as a useful tool for the identification of asymptomatic PAD and as an important marker for systemic atherosclerosis[28]. However, ABPI may have limited value in patients with diabetes or chronic renal failure on hemodialysis as they tend to have calcified vessel walls and with other factor increasing vessel stiffness.

\section{Conclusion}

Our study was a cross sectional observational study, here study population are patients admitted in cardiology department for various types of CAD presentation(e.g., SIHD,STEMI,NSTE-ACS) without any history suggestive of PAD. We identify here $10.96 \%$ of patients have PAD (as evidenced by low ABPI, i.e.,<0.9). ABPI and CAG done for every study patients and different established risk factors for atherosclerosis screened. Among the established risk factors, we see here that only Diabetes Mellitus is significantly associated with increased severity of both coronary artery disease(i.e., high Syntax score) as well as with increased severity of peripheral artery disease(i.e., low ABPI). This is statistically significant in both the cases. Among other factors increase of age is statistically significantly associated with increased severity of coronary artery disease(i.e. high Syntax score), But not with Peripheral artery disease. Other factors like dyslipidemia, obesity, hypertension, family history of premature CAD, smoking habit found not to be significantly associated with severity of CAD as well as with PAD.

Here we also see that ABPI and Syntax score are inversely correlated, and it is statistically significant. So, we may conclude that patient who have a low ABPI,have a chance to have a severe coronary artery disease. This observation also supports the notion that atherosclerosis is a polyvascular disease and it is a generalised process, not limiting to any vascular territory. The ABPI, a simple, and well-established method for diagnosing patients with PAD, can be used to predict potential hazards in patients suspected of having CAD in a clinical setting. The present study confirmed that the ABPI could predict individuals with complex lesion subtypes that have been demonstrated to influence procedural and inhospital outcomes following subsequent intervention. Low ABPI values indicated high Syntax score, which are potential risk factors for atherosclerosis and atherosclerosis-related complications such as cardiovascular morbidities and mortalities, stroke evidence, and increased rate of MS occurrence. These conclusions can be extended particularly to patients with DM.

Our study result is comparable with previous study results performed by Korkmaz et al [24] and Benyakorn et al [25] but ours is a small study, so further study with larger population base is necessary to conclude the above facts undoubtedly.

\section{Study Limitation}

Firstly,ours is a small study with only 219 study population.

Secondly, this study was an observational non-randomized and might be subjected to selection bias. Thirdly, the mean age in our study population was approximately 52 years, suggesting possible exclusion of elderly patients. Fourthly, we analyzed only the presence or absence of risk factors in calculating the atherosclerotic burden but not considered the duration of such risk factors prior to the study evaluation which might have significant impact on findings.

\section{References}

1. Dai X, Wiernek S, Evans JP, Runge MS (2016) Genetics of coronary artery disease and myocardial infarction. World J Cardiol 8 (1): 1-23.

2. Calderon R Jr, Schneider RH, Alexander CN, Myers HF, Nidich SI, et al. (1999) Stress, stress reduction and hypercholesterolemia in African Americans: a review. Ethn Dis 9(3): 451-462.

3. Kivimäki M, Nyberg ST, Batty GD, Fransson EI, Heikkilä K, et al. (2012) Job strain as a risk factor for coronary heart disease: a collaborative meta-analysis of individual participant data. Lancet 380(9852): 14911497.

4. Kannel WB, Vasan RS (2009) Triglycerides as vascular risk factors: new epidemiologic insights. Curr opin cardiol 24(4): 345-350.

5. Scientific Report of the 2015 Dietary Guidelines Advisory Committee" (PDF). health. gov. Feb 2015. p. Part D, Chapter 1, p. 17 (642).

6. (2012) What Is Peripheral Vascular Disease? (PDF). https://www. heart.org.

7. Fowkes FG, Rudan D, Rudan I, Aboyans V, Denenberg JO, et al. (2013) Comparison of global estimates of prevalence and risk factors for peripheral artery disease in 2000 and 2010: a systematic review and analysis. Lancet 382(9901): 1329-1340.

8. Andras A, Ferket B (2014) Screening for peripheral arterial disease. Cochrane Database Syst Rev 4: CD010835.

9. U.S. Preventive Services Task Force (2014) "Peripheral artery disease screening and cardiovascular disease risk assessment with the ankle-brachial index in adults: recommendation statement." Am Fam Physician 90(12): 858A-858D.

10. Bedenis R, Stewart M, Cleanthis M, Robless P, Mikhailidis DP, et al. (2014) Cilostazol for intermittent claudication. The Cochrane database of systematic reviews 10: CD 003748.

11. Hauk L (2012) ACCF/AHA update peripheral artery disease management guideline. Am Fam Physician. 85(10): 1000-1001.

12. Caro J, Migliaccio-Walle K, Ishak KJ, Proskorovsky I (2005) The morbidity and mortality following a diagnosis of peripheral arterial disease: long-term follow-up of a large database. BMC Cardiovasc Disord 5:14. 
13. Nunez D, Morillas P, Quiles J, Cordero A, Guindo J, et al. (2010) Usefulness of an abnormal ankle-brachial index for detecting multivessel coronary disease in patients with acute coronary syndrome. Rev Esp Cardiol 63(1): 54-59.

14. Mlacak B, Blinc A, Pohar M, Stare J (2006) Peripheral arterial disease and ankle-brachial pressure index as predictors of mortality in residents of Metlika County, Slovenia. Croat Med J 47(2): 327-334.

15. Dachun Xu, Jue Li, Liling Zou, Yawei Xu, Dayi Hu, et al. (2010) Sensitivity and specificity of the ankle--brachial index to diagnose peripheral artery disease: a structured review. Vasc Med 15(5): 361-369.

16. Lamina C, Meisinger C, Heid IM, Löwel H, Rantner B, et al. (2006) Association of ankle-brachial index and plaques in the carotid and femoral arteries with cardiovascular events and total mortality in a population-based study with 13 years of follow-up. Eur Heart J 27(21) 2580-2587.

17. Ranucci M, Castelvecchio S, Menicanti L, Frigiola A, Pelissero G (2009) Risk of assessing mortality risk in elective cardiac operations: age, creatinine, ejection fraction, and the law of parsimony. Circulation 119(24): 3053-3061.

18. Garg S, Sarno G, Garcia-Garcia HM, Girasis C, Wykrzykowska J, et al. (2010) A new tool for the risk stratification of patients with complex coronary artery disease: the Clinical SYNTAX Score. Circ Cardiovasc Interv 3(4): 317-326.

19. Windecker S, Remondino A, Eberli FR, Jüni P, Räber L, et al. (2005) Sirolimus-eluting and paclitaxel-eluting stents for coronary revascularization. N Engl J Med 353(7): 653-662.

20. Lakatta EG, Wang M, Najjar SS (2009) Arterial ageing and sub clinical arterial dieases are fundamentally intertwined at macroscopic and molecular levels. Med Clin North Amc 93(3): 583-604.
21. Bhattacharya PJ, Vijapur S, Bhattacharya AK (2016) A study of cardiovascular risk factors correlation with the angiographic severity of coronary artery disease using Syntax score: IOSR Journal of dental and medical science(IOSR-JDMS) 15(1): 21-28.

22. Alderman EL, Corley SD, Fisher LD, Chaitman BR, Faxon DP, et al. (1993) Five-year angiographic follow-up of factors associated with progression of coronary artery disease in the Coronary Artery Surgery Study (CASS). CASS participating investigators and staff. J Am Coll Cardiol 22(4): 1141-1154.

23. Berry C, Noble S, Gregoire JC, Ibrahim R, Levesque S, et al. (2010) Glycaemic status influences the nature and severity of coronary artery disease. Diabetologia 53(4): 652-658.

24. Korkmaz L, Adar A, Erkan H, Ağaç MT, Acar Z, et al. (2012) Anklebrachial index and coronary artery lesion complexity in patients with acute coronary syndromes. Angiology 63(7): 495-499.

25. Benyakorn T, Kuanprasert S, Rerkasem K (2012) A correlation study between ankle brachial pressure index and the severity of coronary artery disease. Int J Low Extrem Wounds 11(2): 120-123.

26. Ahn S, Park YJ, Min SI, Kim SY, Ha J, et al. (2012) High prevalence of peripheral artery disease in Korean patients with coronary or cerebrovascular disease. J Korean Med Sci 27(6): 625-629.

27. Jeremias A, Gruberg L, Patel J, Connors G, Brown DL (2010) Effect of peripheral artery disease on in-hospital outcomes after primary percutaneous coronary intervension for acute myocardial infarction. Am J Cardiol 105(9): 1268-1271.

28. Moussa ID, Jaff MR, Mehran R, Gray W, Dangas G, et al. (2009) Prevalence and prediction of previously unrecognized peripheral artery disease in patients with coronary artery disease: the peripheral artery disease in interventional patients study. Catheter Cardiovasc Interv 73(6): 719724.

Your next submission with Juniper Publishers will reach you the below assets

- Quality Editorial service

- Swift Peer Review

- Reprints availability

- E-prints Service

- Manuscript Podcast for convenient understanding

- Global attainment for your research

- Manuscript accessibility in different formats

( Pdf, E-pub, Full Text, Audio)

- Unceasing customer service

Track the below URL for one-step submission https://juniperpublishers.com/online-submission.php 